\title{
Overlap in the feeding morphology of bivalves from species-rich and species-poor intertidal flats using gill:palp ratios for comparative analyses of mollusc assemblages
}

\author{
Tanya J. Compton ${ }^{1,2,3, *}$, Jan Drent ${ }^{1}$, Rosemarie Kentie ${ }^{1,2}$, Grant B. Pearson ${ }^{3}$, \\ Jaap van der Meer ${ }^{1}$, Theunis Piersma ${ }^{1,2}$ \\ ${ }^{1}$ Department of Marine Ecology and Evolution, Royal Netherlands Institute for Sea Research (NIOZ), \\ PO Box 59, 1790 AB Den Burg, Texel, The Netherlands
}

${ }^{2}$ Centre for Ecological and Evolutionary Studies, University of Groningen, PO Box 14, 9750 AA Haren, The Netherlands

${ }^{3}$ Western Australian Department of Environment and Conservation, Western Australia Wildlife Research Centre, PO Box 51, Wanneroo, Western Australia 6065, Australia

\begin{abstract}
Using morphological variables to describe how species coexist within morphospace, previous studies have shown that species-rich assemblages can (1) show no morphological overlap between species, and (2) occupy a larger morphospace than species-poor assemblages. To describe morphospace occupation in bivalve species from a species-rich tropical (Roebuck Bay, northwestern Australia) and a species-poor temperate (Wadden Sea, The Netherlands) intertidal flat, we used a functional trait that has a clear ecological interpretation: bivalve feeding morphology. Bivalve feeding morphology can be represented by the dimensionless log-ratio of the size of the pumping apparatus (gills) to the size of the sorting apparatus (palps). This log gill-to-palp mass ratio is tightly related to both feeding mode and environment. At both intertidal flats, the log gill-to-palp mass ratios of all species sampled fell along a continuous gradient from those typical of deposit feeders to those typical of suspension feeders. Surprisingly, the log gill-to-palp mass ratios of the species-rich assemblage at Roebuck Bay displayed greater morphological overlap within a larger total occupied morphospace than the species-poor assemblage at the Wadden Sea. The larger total morphospace at Roebuck Bay appears to reflect greater species richness and broader environmental ranges. Because gills and palps of bivalves are easily measured, we propose that they provide a basis for further morphospace comparisons among communities, e.g. along entire latitudinal, depth or productivity gradients.
\end{abstract}

KEY WORDS: Morphology - Functional trait $\cdot$ Bivalve $\cdot$ Ctenidia $\cdot$ Labial palps $\cdot$ Community structure $\cdot$ Diversity $\cdot$ Morphospace

\section{INTRODUCTION}

For species to coexist within increasingly diverse (e.g. tropical) assemblages, MacArthur (1972) proposed that the niche packing of species would change along an axis of competition either by a decrease in niche width, an increase in the total niche space or greater niche overlap. However, greater niche overlap between species goes against the prediction of the limiting similarity hypothesis, which assumes that coexistence between species is maintained by niche differentiation (MacArthur \& Levins 1967). Niche packing between species-rich and species-poor assemblages has been described by morphospace occupation (Ricklefs \& Miles 1994). Morphospace is an $n$-dimensional hypervolume where the axes are morphological vari- 
ables, e.g. the feeding apparatus of fishes (Bellwood et al. 2006). A species can occupy a part of this total morphospace, and the assemblage of species determines the total morphospace occupied (Ricklefs \& O'Rourke 1975, Roy \& Foote 1997).

Comparisons between assemblages of birds, bats, lizards and fishes suggest that species at taxonomically diverse sites display the same morphological differentiation as less diverse sites, but occupy a larger total morphospace (Ricklefs \& Miles 1994). Such morphological differences are often interpreted in line with the limiting similarity hypothesis (Ricklefs \& Travis 1980, Ricklefs \& Miles 1994). Intriguingly, 2 recent studies of gastropod shell shape and fish feeding morphology document considerable morphological overlap between species (Roy et al. 2001, Bellwood et al. 2006). This overlap was partly attributed to phylogenetic constraints, and, in the case of fish feeding morphology, to flexibility in feeding strategies.

McGill et al. (2006) emphasise that we need clear and interpretable axes to examine morphospace occupation. An example of a clear functional trait is the feeding morphology of bivalves as represented by the dimensionless ratio of the size of the pumping (gills) to sorting (palps) apparatus, log transformed to ensure normality. The log gill-to-palp mass ratio reflects a continuum between the 2 main feeding modes: suspension- and deposit-feeding (Fig. 1). Large gills and small palps, i.e. high ratios, are characteristic of suspension-feeding bivalves, with the gills pumping large amounts of water with relatively scarce phytoplankton food items onto the palps (Jørgensen 1966). In contrast, large palps and small gills, i.e. small ratios, are characteristic of deposit-feeding bivalves, where the gills

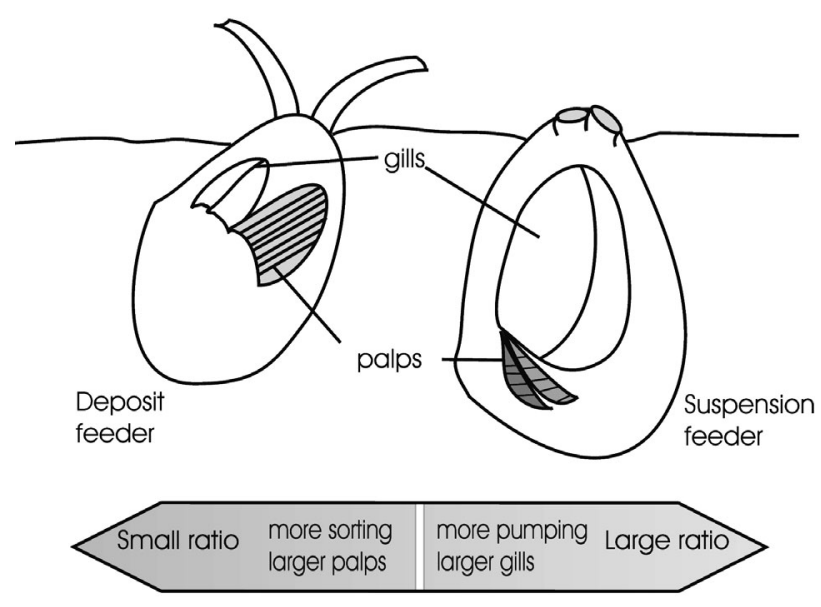

Fig. 1. Feeding organs from typical deposit- and suspensionfeeding bivalves, both buried near the surface in soft sediment. Deposit feeders have large palps for sorting food from sediment, whereas suspension feeders have large gills for pumping water with planktonic food items pump high sediment loads and food particles onto the palps where they are sorted (Yonge 1949). Within this spectrum of suspension- and deposit-feeding morphology, it has also been demonstrated that the mechanisms associated with particle feeding and selection are complex, including species-specific processes that involve selection based on physical and chemical characteristics of food particles (Ward \& Shumway 2004).

Underscoring the functional relevance of the log gillto-palp mass ratio, the feeding environment (e.g. turbidity of the overlying water and sediment characterisation) of several bivalve species is reflected by the relative sizes of the gills and palps (Essink et al. 1989, Barille et al. 2000, Honkoop et al. 2003, Drent et al. 2004). In turbid waters, suspension feeders increase their palp size and, thus, their sorting capacity (Payne et al. 1995a,b). In the deposit-feeding bivalve Macoma balthica, palp size also increased in relation to mud content both in the field and under experimental conditions (Drent et al. 2004). Because bivalve gills and palps are easily measured morphological variables, we propose that they provide an ideal set of axes for morphospace comparisons among species assemblages.

In the present study, we describe morphospace occupation in bivalves from a species-rich tropical (Roebuck Bay, northwestern Australia) and a species-poor temperate (Wadden Sea, The Netherlands) intertidal flat using the log gill-to-palp mass ratio. Morphospace occupation at each intertidal flat is described as (1) the total morphospace occupied, (2) the part of morphospace occupied by each species, and (3) the amount of morphological overlap between species using 2 measures: morphological overlap and nearest-neighbour distance.

\section{MATERIALS AND METHODS}

Bivalve collection. Bivalves were collected from Roebuck Bay, northwestern Australia $\left(17^{\circ} \mathrm{S}\right.$ and $\left.122^{\circ} \mathrm{E}\right)$ and the western part of the Wadden Sea, The Netherlands $\left(53^{\circ} \mathrm{N}\right.$ and $\left.5^{\circ} \mathrm{E}\right)$ in 2003 and 2004 from a variety of sites within each location. Environmental differences between the 2 tidal flats include temperature, chlorophyll a (chl a) (organic content), tidal range and sediment characterisation.

The mudflat of Roebuck Bay is subject to relatively constant warm temperatures (average $28.6 \pm 2.8^{\circ} \mathrm{C}$, range: 15.5 to $37.5^{\circ} \mathrm{C}$ ), and the Wadden Sea mudflat is subject to more variable lower temperatures (average $11.8 \pm 6.6^{\circ} \mathrm{C}$, range: -0.4 to $28.1^{\circ} \mathrm{C}$ ) (Compton et al. in press). In Roebuck Bay, chl a values were low and ranged between $0.7 \pm 0.4 \mathrm{mg} \mathrm{l}^{-1}$ over a $3 \mathrm{yr}$ period (Rose et al. 1990), whereas chl a values were approximately 10 -fold higher (average of approx. $7.26 \mathrm{mg} \mathrm{l}^{-1}$ over 
$27 \mathrm{yr}$ ) in the Wadden Sea (Cadée \& Hegeman 2002). Tidal inundation at Roebuck Bay is large, from $3.5 \mathrm{~m}$ at neap to $8.5 \mathrm{~m}$ at spring tide, whereas the Wadden Sea exhibits a tidal range from $1.5 \mathrm{~m}$ at neap to $2 \mathrm{~m}$ at spring tide (Pepping et al. 1999). A larger range of sediment grain sizes occurs at Roebuck Bay relative to the sampled parts of the Wadden Sea (Pepping et al. 1999, Piersma et al. 2001). Reflecting the difference in sedimentary environment between the 2 intertidal flats, the bivalves from the Wadden Sea were collected from a gradient of sandier sediments (86 to $245 \mu \mathrm{m}$ median grain size) than the Roebuck Bay bivalves. The latter were collected from a range of very muddy to coarse sandy sediments (13 to $380 \mu \mathrm{m}$ median grain size).

The Roebuck Bay assemblage is more diverse (65 species, Pepping et al. 1999) than the Wadden Sea assemblage (16 species, Wolff 1983). At each location the aim was to collect as many species as possible from a variety of sites at different times of the year. Using knowledge of bivalve distributions (Beukema 1976, Pepping et al. 1999), we tried to ensure that species were sampled from the entire area. A variety of collection methods were used: (1) brooming the mud on the out-going tide; (2) sieving the sediment through a $1 \mathrm{~mm}$ sieve; (3) digging in the mud with our hands; and (4) dredging the muddy sediments. We collected approximately half (30 species) of the species known in Roebuck Bay, and more than half (10 species) of the species known in the Wadden Sea. The sampled species represent the majority of bivalve biomass at both locations (Wolff 1983, Pepping et al. 1999).

Bivalve feeding morphology. After collection in the field, live bivalves were stored in fresh seawater. Dissection of live bivalves was completed within 24 to $48 \mathrm{~h}$ under a binocular microscope. Using surgical forceps, the gills and palps were separated and dried in platinum crucibles for $3 \mathrm{~d}$ at $60^{\circ} \mathrm{C}$, and then cooled in a desiccator and weighed to the nearest $0.1 \mathrm{mg}$ (Mettler Toledo AE 160 balance). Following weighing, gills and palps were incinerated at $560^{\circ} \mathrm{C}$ for $5 \mathrm{~h}$. After cooling, the incinerated samples were reweighed. The difference between the dried and ashed mass is the ash-free dry mass (AFDM). We use the log gill-to-palp mass ratio, as calculated from the gill and palp AFDM, to describe bivalve feeding morphology (Drent et al. 2004). The mass of the gills and palps is an accurate and commonly used (Honkoop et al. 2003, Drent et al. 2004) measurement of these 3-dimensional organs. Measuring the mass rather than the surface area is a preferred method of analysis because surface area does not quantify the folds of the gills and palps accurately.

Morphospace calculations. At each location we describe the part of morphospace occupied by an individual species as an interquartile range. Interquartile ranges are measures of statistical dispersion, i.e. the range between the third and first quartile represents $50 \%$ of the data. We examined if species' interquartile ranges were significantly different between the 2 intertidal flat systems using a 1-way ANOVA. Species at each location were ranked based on their median log gill-to-palp mass ratios, and a Pearson correlation was used to examine if the rank value of the log gill-to-palp mass ratio was correlated with the interquartile range of each species.

To define the total morphospace occupied by bivalves at the 2 locations, 2 different measures were applied: (1) the standard deviation of the species' means of log gill-to-palp mass ratio; (2) the total range occupied between the highest third quartile of the largest species and the smallest first quartile of the smallest species of the log gill-to-palp mass ratio. Because the total range occupied is determined by the difference between the highest third and lowest first quartile, this might lead to an upward bias in the estimate of total morphospace occupied due to the greater number of species sampled in the species-rich Roebuck Bay. We ran a Monte Carlo randomization simulation (1000 times, with replacement) on the Roebuck Bay species to control for such a bias due to sampling more species. For each simulation, 10 species were randomly selected, the same number of species as sampled in the Wadden Sea, and the total range occupied was calculated. To estimate the probability of a larger total morphospace occupied in the Roebuck Bay assemblage, we estimated the proportion of values where the total range occupied in Roebuck Bay was greater than the total range occupied by the Wadden Sea assemblage.

To determine how total morphospace was occupied by species at each location, an average nearestneighbour distance and an average morphological overlap value was estimated. The nearest-neighbour distance between species was calculated by subtracting the median log gill-to-palp mass ratios of ranked neighbours. Then an average nearest-neighbour distance was calculated for all bivalves at each location. A 1-way ANOVA was used to test whether the nearestneighbour distances in Roebuck Bay were different from those of the Wadden Sea. Morphological overlap was calculated by summing each species' interquartile range and dividing this value by the total range occupied. We re-ran all calculations after removing the species with a low sample size ( $\mathrm{n}<10$ individuals) in Roebuck Bay to check that these species samples did not affect the overall conclusions ( $\mathrm{N}=20$ species tested).

Phylogenetic analyses. A test for serial independence was run (Abouheif 1999, Reeve \& Abouheif 2003) to examine whether the bivalve feeding morphology was phylogenetically constrained (Harvey \& 
Pagel 1991). The phylogenetic topology of the bivalve species was drawn from Giribet \& Wheeler (see Fig. 11, p. 296, in Giribet \& Wheeler 2002) and family descriptions in Beesley et al. (1998). In Roebuck Bay, although some species have not received formal names, genetic analyses have shown that the species are genetically distinct (P. C. Luttikhuizen et al. unpubl.).

To determine whether morphological overlap is driven solely by phylogeny, a measure of taxonomic distinctness $\left(\Delta^{+}\right)$was calculated for the Roebuck Bay and Wadden Sea assemblages, and for a randomly subsampled set of Roebuck Bay species $(n=10)$ multiple times ( $\mathrm{n}=25)$ (Clarke \& Warwick 1998). These values were then correlated with morphological overlap.

\section{RESULTS}

Ranking the species by median log gill-to-palp mass ratios (Fig. 2) showed an almost continuous gradient within each assemblage. In addition, the interquartile ranges of species within the Roebuck Bay assemblage were correlated with their rank value, which indicates that deposit-feeding species generally have smaller interquartile ranges, whereas suspension-feeding species generally have larger interquartile ranges ( $\mathrm{r}=$ $-0.60, \mathrm{~N}=30, \mathrm{p}<0.01$ ). This trend was not apparent in the Wadden Sea assemblage $(r=-0.28, N=10, p=$ 0.43).

The standard deviation of the species' mean log gillto-palp mass ratios indicated that the Roebuck Bay assemblage occupied a larger total morphospace (Roebuck Bay: $\mathrm{SD}=0.46, \mathrm{~N}=30$ ) than the Wadden Sea assemblage $(\mathrm{SD}=0.37, \mathrm{~N}=10$, Table 1 ), even when species with small sample sizes were excluded ( $\mathrm{SD}=0.45, \mathrm{~N}=20$ ). The total range occupied, between the highest third quartile of the largest species and the smallest first quartile of the smallest species, also showed that the total morphospace in the Roebuck Bay assemblage is larger (Roebuck Bay: $1.60, \mathrm{~N}=30$ or $1.44, \mathrm{~N}=20$, vs. Wadden Sea: $1.11, N=10$, log gill-to-palp mass ratios, Fig. 2). Taking the unequal number of sampled species into account with a Monte Carlo randomization, the difference in the total morphospace occupied was significant for the entire dataset (Fig. 3A, p = 0.04) and marginally insignificant when species with small sample sizes were excluded (Fig. 3B, p=0.07).

Despite the larger total morphospace occupied in the Roebuck Bay assemblage, the bivalves here had a higher amount of morphological overlap (3.30, $\mathrm{N}=30$ and 1.77, $\mathrm{N}=$ 20; $\log$ gill-to-palp mass ratios) than the Wadden Sea bivalves (1.17, $N=10)$. Furthermore, a decrease in species' interquartile ranges at each location was not evident $\left(F_{1,38}=0.98, \mathrm{p}=0.33\right.$ or $F_{1,28}=0.02, \mathrm{p}=0.88$, Table 1). Instead, there was a trend for species in Roebuck Bay to be more tightly packed within the total morphospace occupied, with much smaller average nearest-neighbour distances in Roebuck Bay $(0.05 \pm 0.05, \mathrm{~N}=30$ or $0.07 \pm 0.08, \mathrm{~N}=20)$ than in the Wadden Sea $(0.11 \pm 0.08, N=10)$. A 1 -way ANOVA showed a significant difference in the nearestneighbour distances between Roebuck Bay and the Wadden Sea assemblages when all species were compared $\left(F_{1,36}=7.47, \mathrm{p}=0.01\right)$, but did not remain significant when species with low sample sizes were excluded $\left(F_{1,26}=1.59, \mathrm{p}=0.22\right)$.

The phylogenetic test for serial independence of log gill-to-palp mass ratios yielded a significant result ( $\mathrm{p}=$ 0.01 ), indicating that the distribution of log gill-to-palp mass ratios in the total morphospace occupied is significantly affected by phylogeny. This can also be seen in the ranking of log gill-to-palp mass ratios (Fig. 2); i.e. the Tellinidae species in Roebuck Bay, and to a certain extent in the Wadden Sea, share similar log gill-to-palp mass ratios. Furthermore, in Roebuck Bay the 2 protobranch species (Nucula sp. and Ledella sp.) share similar rankings.

There was no correlation between morphological overlap and taxonomic distinctness for the subsampled set $(n=10)$ of Roebuck Bay species $(n=25, R=0.29, p>$ $0.05,2.6<\Delta^{+}>4.6$ for random sampled species, cf. $\Delta^{+}=$

Table 1. Morphospace calculations from medians and quartiles on the basis of log gill-to-palp mass ratios for the species-rich Roebuck Bay and the speciespoor Wadden Sea. All calculations in the Wadden Sea were completed with the same number of species $(\mathrm{N}=10)$, whereas Roebuck Bay calculations were completed for all species $(\mathrm{N}=30)$, and for species with higher sample sizes only $(\mathrm{n}>10, \mathrm{~N}=20)$

\begin{tabular}{|lcccccc|}
\hline \multirow{2}{*}{ Variable } & \multicolumn{3}{c}{ Roebuck Bay } & \multicolumn{3}{c|}{ Wadden Sea } \\
& $\mathrm{N}$ & Mean & $\mathrm{SD}$ & & Mean & $\mathrm{SD}$ \\
\hline Occupied morphospace & 30 & 0.27 & 0.46 & 0.23 & 0.37 \\
& 20 & 0.17 & 0.45 & & \\
Total occupied range & 30 & 1.60 & & 1.11 & \\
& 20 & 1.44 & & & \\
Species' interquartile ranges & 30 & 0.16 & 0.10 & 0.13 & 0.03 \\
& 20 & 0.13 & 0.06 & & \\
Overlap between species & 30 & 3.03 & & \multirow{2}{*}{1.17} & \\
& 20 & 1.77 & & & \\
Nearest-neighbour distance & 30 & 0.05 & 0.05 & 0.11 & 0.08 \\
& 20 & 0.07 & 0.08 & & \\
\hline
\end{tabular}




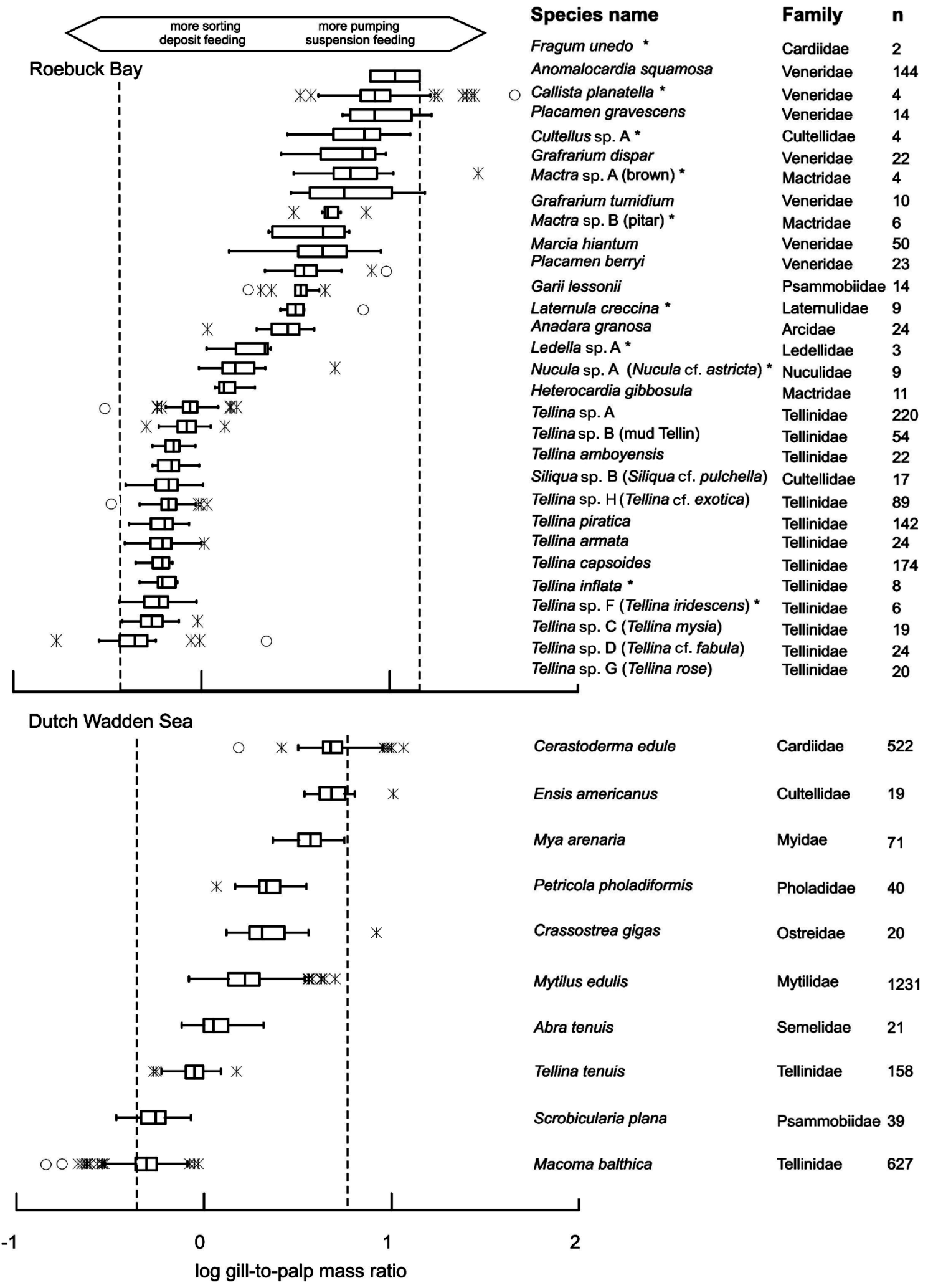

Fig. 2. Ranked log gill-to-palp mass ratios of bivalves in Roebuck Bay and the Wadden Sea display a gradient between mostly sorting (deposit feeding) and mostly pumping (suspension feeding), within the total range of morphospace occupied at each location, as indicated by the verticle dashed lines. Number of individuals (n) collected for each species is shown. ${ }^{*}$ : species with a low sample size $(\mathrm{n}<10)$. Boxplots show the median and the upper and lower quartile of log gill-to-palp mass ratios; whiskers show the range of values outside of the box. O: large outliers; $*$ : small outliers 


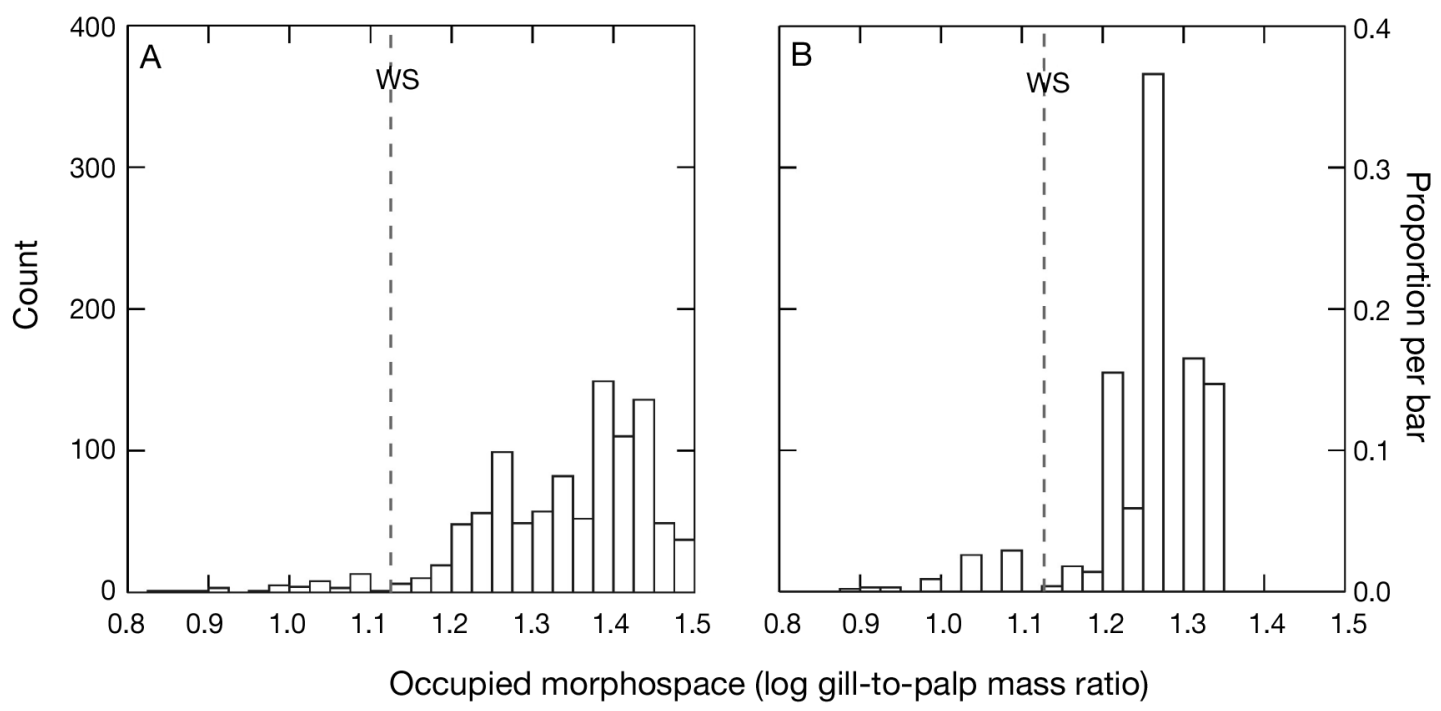

Fig. 3. Frequency distributions of the total occupied morphospace expected if only 10 bivalve species are randomly sub-sampled 1000 times from the $(\mathrm{A})$ total Roebuck Bay dataset $(\mathrm{N}=30)$ or the $(\mathrm{B})$ reduced Roebuck Bay dataset $(\mathrm{N}=20)$ where species with a small sample size $(\mathrm{n}<10)$ are removed. The total occupied morphospace expected in Roebuck Bay is (A) significantly larger than the Wadden Sea when species are sub-sampled $(\mathrm{N}=30, \mathrm{p}=0.04)$, but $(\mathrm{B})$ marginally insignificant when small sample size species are excluded $(\mathrm{N}=20, \mathrm{p}=0.07$, Fig. $3 \mathrm{~b})$. Dashed verticle line indicates the observed total occupied morphospace of the Wadden Sea (WS) assemblage

3.91 for the 30 sampled Roebuck Bay species). In all cases, the taxonomic distinctness of the Roebuck Bay assemblage was lower than that of the Wadden Sea assemblage $\left(\Delta^{+}=4.91\right)$. The morphological overlap values for these randomizations were similar even though the taxonomic distinctness was variable. This suggests that morphological overlap is not driven by taxonomic distinctness alone.

\section{DISCUSSION}

At both locations, the log gill-to-palp mass ratios of bivalves fall along a gradient from small values typical of deposit-feeding species to large values typical of suspension-feeding species (Beesley et al. 1998). This indicates the use of a wide spectrum of feeding modes at each location. However, within the Roebuck Bay assemblage, the log gill-to palp mass ratios displayed a striking amount of morphological overlap within the larger total morphospace occupied. Part of the high morphological overlap is correlated with phylogeny, e.g. members of the family Tellinidae show considerable overlap in log gill-to-palp mass ratios typical of deposit feeders. Phylogeny plays an important role in morphospace occupation, as genetic relatedness is an inherent property of the natural systems that we investigate; however, it is not solely responsible for the morphological overlap, as the taxonomic distinctness values indicated no correlation with morphological overlap. An overlap in log gill-to-palp mass ratios suggests that families such as the Tellinidae may have diversified along other niche axes, for example, a sedimentary axis (van der Meer 1991), or an anti-predation axis including shell strength (Vermeij 1978) and burying depth (Stanley 1970). Morphological overlap may also be indicative of flexibility in feeding mode and diet in changing environments (Bellwood et al. 2006). Currently, we know that such phenotypic flexibility (Piersma \& Drent 2003) exists in some of the Wadden Sea species (Essink et al. 1989, Drent et al. 2004), but we do not know whether it occurs in species from Roebuck Bay. Bellwood et al. (2006) suggest that flexibility in function, expressed as morphological overlap, may be instrumental in maintaining biodiversity.

The total occupied morphospace as determined by 2 different measures (the standard deviation of the species' means of log gill-to-palp mass ratios and total range occupied) showed that the total morphospace occupied in the tropical assemblage was larger than in the temperate assemblage. The larger total morphospace occupied by the Roebuck Bay assemblage is consistent with previous studies (reviewed by Ricklefs \& Miles 1994) where explanations for larger morphospace occupation have included a more varied physical environment, a greater amount of feeding possibilities (Schoener 1971) or the presence of older evolutionary groupings (Ricklefs 2005). However, ecological factors are also expected to play a role; thus, we hypothesize that the larger sediment and tidal ranges 
at Roebuck Bay (Pepping et al. 1999), compared to the studied areas within the Wadden Sea (Piersma et al. 2001), also contribute to the amount of total morphospace occupied.

We acknowledge that this study encompassed 2 locations at extreme ends of a species richness gradient. Comparisons of log gill-to-palp mass ratios at a number of different tidal flats, along various environmental axes (e.g. latitude, depth, primary productivity) are needed to determine whether morphospace occupation at other locations display similar patterns. Strikingly, our findings are in agreement with 2 other recent studies, suggesting that morphological overlap between species may be a more general phenomenon in the tropics (Roy et al. 2001, Bellwood et al. 2006). Here, we propose that the differences in morphospace occupation observed are a good starting point for future in-depth morphospace explorations at the level of assemblages and communities (see McGill et al. 2006). Furthermore, work focusing on the functionality of the gill-to-palp mass ratio might bring understanding to general patterns such as the latitudinal gradient in mollusc species richness (Roy et al. 2000).

Acknowledgements. For help in the field we thank G. Morton, H. Sombroek, K. Krans, R. de Jonge, I. Veltheim and M. Lapwood. We are also grateful for the use of the facilities at the Broome TAFE Aquaculture Centre, Western Australia Fisheries, the Broome Conservation and Land Management office and the Broome Bird Observatory. Identifications of species were completed by M. Lavaleye and R. Willan. We thank R. E. Ricklefs, W. J. Wolff, W. K. Vahl, M. J. A. Rijkenberg, P. J. C. Honkoop, B. L. Bayne and editor L. A. Levin for their valuable comments at various stages. We also thank anonymous referees for their constructive comments on the manuscript.

\section{LITERATURE CITED}

Abouheif E (1999) A method for testing the assumption of phylogenetic independence in comparative data. Evol Ecol Res 1:895-909

Barille L, Haure J, Cognie B, Leroy A (2000) Variation in pallial organs and eulatero-frontal cirri in response to high particulate matter concentrations in the oyster Crassostrea gigas. Can J Fish Aquat Sci 57:837-843

Beesley PL, Ross GJB, Wells A (1998). Mollusca: the southern synthesis. CSIRO Publishing, Melbourne

Bellwood DR, Wainwright PC, Fulton CJ, Hoey AS (2006) Functional versatility supports coral reef biodiversity. Proc R Soc Lond B 273:101-107

Beukema JJ (1976) Biomass and species richness of macrobenthic animals living on the tidal flats of the Dutch Wadden Sea. Neth J Sea Res 10:236-261

Cadée GC, Hegemann J (2002) Phytoplankton in the Marsdiep at the end of the 20th century; 30 years monitoring biomass, primary production, and phaeocystis blooms. J Sea Res 48:97-110

Clarke KR, Warwick RM (1998) A taxonomic distinctness index and its statistical properties. J Appl Ecol 35:523-531
Compton TJ, Rijkenberg MJA, Drent J, Piersma T (in press) Thermal tolerance ranges and climate variability: a comparison between bivalves from differing climates. J Exp Mar Biol Ecol

Drent J, Luttikhuizen PC, Piersma T (2004) Morphological dynamics in the foraging apparatus of a deposit feeding marine bivalve: phenotypic plasticity and heritable effects. Funct Ecol 18:349-356

Essink K, Tydeman P, Koning Fd, Kleef HL (1989) On the adaptation of the mussel Mytilus edulis L. to different environmental suspended matter concentrations. In: Klekowski RZ, Styczynska-Jurewicz E (eds) Proc 21st Eur Mar Biol Symp Gdansk, 14-19 Sep 1986. Polish Academy of Sciences, Institute of Oceanology, Wroclaw, p 41-51

Giribet G, Wheeler W (2002) On bivalve phylogeny: a highlevel analysis of the Bivalvia (Mollusca) based on combined morphology and DNA sequence data. Invertebr Biol 121:271-324

Harvey PH, Pagel MD (1991) The comparative method in evolutionary biology. Oxford University Press, Oxford

Honkoop PJC, Bayne BL, Drent J (2003) Flexibility of size of gills and palps in the Sydney rock oyster Saccostrea glomerata (Gould, 1850) and the Pacific oyster Crassostrea gigas (Thunberg, 1793). J Exp Mar Biol Ecol 282:113-133

Jørgensen CB (1966) Biology of suspension feeding. Pergamon Press, Oxford

MacArthur RH (1972) Geographical ecology. Princeton University Press, Princeton, NJ

MacArthur R, Levins R (1967) Limiting similarity convergence and divergence of coexisting species. Am Nat 101: 377-385

McGill BJ, Enquist BJ, Weiher E, Westoby M (2006) Rebuilding community ecology from functional traits. Trends Ecol Evol 21:178-185

Payne BS, Lei J, Miller AC, Hubertz ED (1995a) Adaptive variation in palp and gill size of the zebra mussel (Dreissena polymorpha) and Asian clam (Corbicula fluminea). Can J Fish Aquat Sci 52:1130-1134

Payne BS, Miller AC, Lei J (1995b) Palp to gill area ratio of bivalves - a sensitive indicator of elevated suspendedsolids. Regul Rivers Res Manag 11:193-200

Pepping M, Piersma T, Pearson GB, Lavaleye M (1999) Intertidal sediments and benthic animals of Roebuck Bay, Western Australia. NIOZ report 1999/3, Neth Inst Sea Res, Texel

Piersma T, Drent J (2003) Phenotypic flexibility and the evolution of organismal design. Trends Ecol Evol 18:228-233

Piersma T, Koolhaas A, Dekinga A, Beukema JJ, Dekker R, Essink K (2001) Long-term indirect effects of mechanical cockle-dredging on intertidal bivalve stocks in the Wadden Sea. J Appl Ecol 38:976-990

Reeve J, Abouheif E (2003) Phylogenetic independence, Version 2.0. Department of Biology, McGill University, Montreal

Ricklefs RE (2005) Small clades at the periphery of passerine morphological space. Am Nat 165:651-659

Ricklefs RE, Miles DB (1994) Ecological and evolutionary inferences from morphology: an ecological perspective. In: Wainwright PC, Reilly SM (eds) Ecological morphology: integrative organismal biology. The University of Chicago Press, Chicago, IL, p 13-41

Ricklefs RE, O'Rourke K (1975) Aspect diversity in moths: a temperate-tropical comparison. Evolution 29:313-324

Ricklefs RE, Travis J (1980) A morphological approach to the study of avian community organization. Auk 97:321-338

Rose RA, Dybdahl RE, Harders S (1990) Reproductive cycle of the Western Australian silverlip pearl oyster, Pinctada 
maxima (Jameson) (Mollusca: Pteriidae). J Shellfish Res 9:261-272

Roy K, Foote M (1997) Morphological approaches to measuring biodiversity. Trends Ecol Evol 12:277-281

Roy K, Jablonski D, Valentine JW (2000) Dissecting latitudinal diversity gradients: functional groups and clades of marine bivalves. Proc R Soc Lond B 267:293-299

Roy K, Balch DP, Hellberg ME (2001) Spatial patterns of morphological diversity across the Indo-Pacific: analyses using strombid gastropods. Proc R Soc Lond B 268:2503-2508

Schoener TW (1971) Large-billed insectivorous birds: a precipitous diversity gradient. Condor 73:154-160

Stanley SM (1970) Relation of shell form to life habits of the Bivalvia (Mollusca). Memoir 125, Geological Society of America, Boulder, CO

Editorial responsibility: Lisa Levin (Contributing Editor), La Jolla, California, USA van der Meer J (1991) Exploring macrobenthos-environment relationship by canonical correlation analysis. J Exp Mar Biol Ecol 148:105-120

Vermeij GJ (1978) Biogeography and adaptation: patterns of marine life. Harvard University Press, Cambridge, MA

Ward JE, Shumway SE (2004) Separating the grain from the chaff: particle selection in suspension- and deposit-feeding bivalves. J Exp Mar Biol Ecol 300: $83-130$

Wolff WJ (1983) Ecology of the Wadden Sea. Balkema, Rotterdam

Yonge CM (1949) On the structure and adaptations of the Tellinacea, deposit-feeding Eulamellibranchia. Phil Trans R Soc Lond B 234:29-76

Submitted: December 19, 2006; Accepted: May 21, 2007 Proofs received from author(s): October 8, 2007 